\title{
PARAMETERS IN PANORAMIC RADIOGRAPHY FOR DIFFERENTIATION OF RADIOLUCENT LESIONS
}

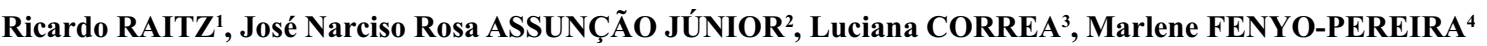

\begin{abstract}
1- DDS, MSc, PhD, Full Professor, Department of Biodentistry, Dental School, Ibirapuera University, São Paulo, SP, Brazil.
2-DDS, MSc, Graduate student, Department of Biodentistry, Dental School, Ibirapuera University, São Paulo, SP, Brazil.

3- DDS, MSc, PhD Assistant Professor, Department of Stomatology, Dental School, University of São Paulo, São Paulo, SP, Brazil.

4- DDS, MSc, PhD, Associate Professor, Department of Stomatology, Dental School, University of São Paulo, São Paulo, SP, Brazil.
\end{abstract}

Corresponding address: Prof. Dr. Ricardo Raitz - Rua Heitor Penteado 1832, 101/A - São Paulo, SP, Brasil - 05438-300 - Phone: +55-11-3673-5270 -

Fax: +55-11- 3673-5270 - e-mail: ricardoraitz@ig.com.br

Received: July 24, 2008 - Modification: November 2, 2008 - Accepted: May 27, 2009

\begin{abstract}
$O$

bjective: The aims of this study were to establish parameters in panoramic radiography for interpretation of unilocular radiolucent lesions, and to compare the accuracy of diagnoses given by examiners before and after using these parameters. Material and Methods: In Part I, 12 specialists analyzed 24 images and the diagnostic criteria used by each examiner to make correct diagnoses were used to build a list of basic radiographic parameters for each pathology (ameloblastoma, keratocystic odontogenic tumor, dentigerous cyst, and idiopathic bone cavity). In Part II, this list was used by 6 undergraduate students (Un), 8 recently graduated dentists (D), 3 oral pathologists, 3 stomatologists, 3 oral radiologists, and 3 oral surgeons to diagnose the corresponding pathologies in the other set of 24 panoramic radiographs (T2). The same analysis occurred without using this list (T1). The method of generalized estimating equations (GEE) was used in order to estimate the probability of making a correct diagnosis depending on the specialty of the examiner, type of lesion, and moment of the evaluation, T1 or T2 (before or after they had access to the list of parameters, respectively). Results: Higher values were obtained for the probability (GEE) of making a correct diagnosis on T2; the group Un presented the highest improvement (14.6\%); no differences between the probabilities were observed either between Un and D, or among the different groups of specialists. Conclusions: The use of panoramic radiographic parameters did allow improving the diagnostic accuracy for all groups of examiners.
\end{abstract}

Key words: Image interpretation. Jaw diseases. Differential diagnosis. Education. Radiologic parameters. Radiolucent lesions.

\section{INTRODUCTION}

The diagnostic process of jawbone lesions is complex since several etiologic factors, histopathological findings, morphological details, and distinct radiographic characteristics are involved ${ }^{16}$. Unilocular radiolucent lesions have similar clinical and radiographic characteristics, although they have different histopathological aspects, biological behavior, and treatment ${ }^{9}$. This is especially true for ameloblastoma, keratocystic odontogenic tumor, dentigerous cyst, and idiopathic bone cavity (simple bone cyst). These lesions may show a unilocular and well-defined radiolucent image with well corticated borders, presenting or not presenting an unerupted tooth ${ }^{18}$. These possibilities for the above lesions make their radiographic differentiation a difficult task ${ }^{14}$.

Diagnosis can be established or better understood by carefully analyzing the site of the lesion, its borders and radiographic aspect, as well as the effect of the lesion on adjacent structures. The presence and extension of cortical erosion and root resorption or divergence can also aid in establishing a diagnosis, ${ }^{4,21}$. A number of imaging techniques including magnetic resonance imaging ${ }^{12}$, scintigraphy ${ }^{7}$, ultrasonography ${ }^{10}$, computed tomography ${ }^{15}$, conventional ${ }^{5,8,16}$ and digital radiographs ${ }^{17}$ were used to differentiate these lesions. Techniques such as computed tomography provide much more information, but intraoral and panoramic radiographies may be the only imaging techniques available for examination in local health centers. Therefore, dental students and general dental practitioners should first extract the maximum information as possible from them and then look for techniques of higher complexity.

The characteristics of the lesions have already been stated in literature ${ }^{2-7,16,18,21}$. However, they are not compiled together in order to make possible a direct comparison among lesions. While detailed analysis of an image is essential in radiological examination ${ }^{2}$, image interpretations may vary from one examiner to another ${ }^{19}$. Thus, determining radiographic parameters is required in order to establish a correct diagnosis. Such parameters should focus on specific 
radiographic elements, which could allow greater diagnostic accuracy, mainly in the case of lesions of difficult radiographic interpretation, such as the unilocular lesions mentioned above. The main goals of this study were to establish parameters in panoramic radiographs for interpretation of unilocular radiolucent lesions, and to compare the accuracy of diagnoses given by examiners before and after using these parameters.

\section{MATERIAL AND METHODS}

This study was divided into Part I (establishment of radiographic parameters) and Part II (appliance and validation of radiographic parameters), in which 48 radiographs (24 in each part) from different archives were analyzed by 38 examiners. In Part I, 24 panoramic radiographs were selected from archives of the AC Camargo Hospital, 6 of each displayed one of the following pathologies: ameloblastoma (AMEL), keratocystic odontogenic tumor (KOT), dentigerous cyst (DC), and idiopathic bone cavity (IBC). In Part II, 24 other panoramic radiographs were selected from archives of both the Heliópolis Hospital and personal archives of distinct professionals, and were distributed according to the same pathologies analyzed in Part I.

All panoramic radiographs used in this study were analyzed for technical diagnosis by 3 independent radiologists, who were not included in the group of examiners. The unilocular characteristic of the pathologies was also confirmed by computed tomography when necessary. All original histopathological reports were revised by a pathologist, who confirmed the correct diagnosis for each radiography.

All the 48 radiographs were digitalized by using a Microtek ScanMaker $\mu 800$ scanner (MRS-9600TFU2, Microtek Lab, Carson, CA, USA). Standard scanning had a resolution of $600 \mathrm{dpi}$ and image format was TIFF grayscale. Adobe Photoshop $6.0^{\circledR}$ software (Adobe, Mountain View, CA, USA) was used in order to optimize and standardize colors, equalization, brightness, and contrast. Image analyses were performed individually by different groups of examiners, always in the same room and in the same computer (Laptop HP Pavilion ze2000, genuine intel Celeron M processor, $480 \mathrm{MB}$ of Ram; $1.3 \mathrm{GHz}$; 15" monitor, $1024 \times 768$ dpi). Trophy 2000 software (Trophy Windows Access software; Paris, France) was used to analyze the digitalized radiographs. Examiners were informed of the 4 possible diagnoses, but they did not know the proportion of each lesion among the cases. The examiners could also use all the software features as they wish, and no clinical information was given to them.

This protocol was reviewed and accepted by the institutional Ethics Committee.

Part I - Establishment of Radiographic Parameters

Twenty-four image analyses were performed by each of the 12 specialists, who had over 5 -year experience and were professors of different areas: 3 Oral Pathologists (P), 3 Stomatologists (S), 3 Oral Radiologists (R), And 3 Oral Surgeons $(\mathrm{Su})$. The radiographs were presented at random to these examiners and they were asked to establish the most likely diagnosis upon analysis of each radiograph by using only their own diagnosis methods and radiographic experience, and to list the three most important criteria used in establishing their respective diagnoses.

All the criteria used by each examiner in giving the correct diagnoses were evaluated and tabulated. A list was built with the final radiographic parameters used in diagnosing each lesion, within the sample of 24 radiographs, based on the most cited criteria by the examiners (Figure 1). This list of parameters was used by non-specialists and by other 12 specialists in the second part of the study.

\section{Part II - Application and Validation of the Radiographic Parameters}

In this part of the study, 24 radiographs, other than those used in Part I, were analyzed by 3 groups as follows: group Un ( 6 undergraduate dental students, after having concluded the Radiology Discipline); group D (8 dentists - newlygraduated dentists with little experience in oral diagnosis); group Sp (12 specialists with over 5-year experience: 3 oral pathologists- P, 3 stomatologists- S, 3 oral radiologists- R, and 3 oral surgeons- $\mathrm{Su}$ ). The professionals of group $\mathrm{Sp}$ were not the same who participated in Part I of this study.

The radiographs were randomly presented to these 26 examiners, who were asked to establish the most probable diagnosis upon analysis of each radiograph. Analysis of the new 24 radiographs occurred at two different moments, $\mathrm{T}_{1}$ and $\mathrm{T}_{2}$. At moment $\mathrm{T}_{1}$, the examiners used their own methods, experience and criteria and they were also asked to write the three most important criteria used in establishing this first diagnosis. At moment $\mathrm{T}_{2}$ (40 or more days after moment $\mathrm{T}_{1}$ ), the list with the radiographic diagnostic parameters (Figure 1) was given to the examiners before the analysis. At this moment, the examiners were asked to identify the three most important criteria from the chart used when establishing each diagnosis.

\section{Statistical Analysis}

The data were analyzed using generalized estimating equation (GEE) with logistic function and binomial distribution ${ }^{11}$. The GEE approach is adequate for the type of data analyzed here as it allows us to work with dependent measures (repeated measurements at the experimental units that are analyzed by the same professional in distinct moments) and does not follow the normal distribution (in this case, binomial distribution).

A quantitative analysis of the obtained data was carried out and, by using $\mathrm{GEE}^{11}$, the probability of correct diagnosis was calculated taking into account both the examiner specialty and type of lesion. In Part II of this study, a similar analysis was made, in which the time of evaluation $\left(T_{1}\right.$ or $\mathrm{T}_{2}$ ) was included as variable. 


\section{RESULTS}

In Part I of the study, criteria were listed on the basis of diagnoses considered as correct. A quantitative analysis of these criteria allowed building a list of radiographic parameters for diagnosis (Figure 1), that was used in Part II of the experiment. In Part I, the GEE method was used to access the probability of a correct diagnosis and the variables 'type of lesion' and 'examiner's specialty' did not cause significant difference (all with $\mathrm{p}>0.05$ ).

In Part II of the study, 624 responses were obtained from 26 examiners, who analyzed 24 distinct radiographs at moments $T_{1}$ and $T_{2}$ of the evaluation. In Part II, the first diagnostic hypothesis made by each examiner was compared to the correct diagnosis corresponding to each radiography, similarly as in Part I, thus obtaining its classification as correct or incorrect. According to the preliminary inferential analysis using GEE, none of the considered explanatory variables caused significant differences $(p>0.05)$. Thus, since significant differences were not observed between the scores of the four types of specialists, a new model was used in which the following variables were considered: types of lesion (AMEL, IBC, DC, or KOT), moments of evaluation - T1 and T2 (before or after the diagnostic parameters were known), and groups of examiners (undergraduate students, newly-graduated dentists, or specialists). According to this model, the results show that significant differences were not observed among types of lesion $(p=0.105)$. However, significant differences $(p=0.007)$ were observed between moments $\mathrm{T}_{1}$ and $\mathrm{T}_{2}$ of evaluation (the probability of correct answer relative to incorrect answer was significantly higher after diagnostic parameters were known, at moment $\mathrm{T}_{2}$ ). There was also a significant difference $(p=0.003)$ among groups of examiners. The probability of correct answer relative to incorrect answer in the group of specialists was significantly higher than in the group of undergraduate students or in the group of newly-graduated dentists, and these did not show differences between their probabilities of correct answer.

It was observed that the rate $(\%)$ of correct diagnoses increased from 54.3 (before) to $63.5 \%$ after examiners knew the list of diagnostic parameters (Figure 1), respectively. As a whole, the highest rates for correct answers were found among oral surgeons $(\mathrm{Su})$ and stomatologists $(\mathrm{S})$, and the lowest rates were found among radiologists $(\mathrm{R})$ and pathologists (P) (group of specialists). The group of undergraduate students exhibited the highest improvement at moment $\mathrm{T}_{2}(14.6 \%)$, when compared to $\mathrm{T}_{1}$ (Table 1 ).

Table 2 shows the rates for correct answers for all lesions as a function of the groups of examiners. In diagnosing AMEL, all groups showed improvement at moment $T_{2}$. Regarding diagnosis of $\mathrm{DC}$ at moment $\mathrm{T}_{2}$, oral surgeons presented the highest rates for correct answers. In diagnosing IBC at $\mathrm{T}_{2}$, oral surgeons, pathologists and radiologists presented a nearly $20 \%$ improvement in correct answers; stomatologists presented the highest rates for correct answers. For the diagnosis of KOT at $\mathrm{T}_{2}$, undergraduate students and newly-graduated dentists presented a nearly $20 \%$ improvement relative to $T_{1}$. At moment $T_{2}$, the highest rates for correct answers were observed in the group of radiologists.

Regarding lesions as a whole, undergraduate students and newly-graduated dentists presented higher rates for correct answers in the diagnosis of DC and at $\mathrm{T}_{2}$ (63.9 and $77.1 \%$, respectively), and this lesion presented the highest rate of correct answers $(88.9 \%$, as observed in the group of oral surgeons both at $\mathrm{T}_{1}$ and $\mathrm{T}_{2}$ ). KOT presented the lowest rate for correct answers of all lesions, as observed in the groups of undergraduate students and newly-graduated dentists both at $T_{1}$ and $T_{2}$. It is worth emphasizing that undergraduate students and newly-graduated dentists listed few criteria for analysis of the lesions at $\mathrm{T}_{1}$, mainly KOT and IBC.

Table 3 shows a list containing the criteria most used by groups of examiners at $T_{2}$. The two criteria chosen with higher frequency by examiners (Figure 1), both in correct and incorrect responses were selected. In many cases, more than two criteria were listed since they present citation frequencies that were higher and equal.

TABLE 1- Rates (\%) of correct and incorrect answers before $\left(T_{1}\right)$ and after $\left(T_{2}\right)$ diagnostic radiographic parameters were given to distinct groups of examiners

\begin{tabular}{|c|c|c|c|c|}
\hline \multirow[t]{2}{*}{ Groups of examiners } & \multicolumn{2}{|c|}{$\mathrm{T}_{1}$} & \multicolumn{2}{|c|}{$\mathrm{T}_{2}$} \\
\hline & Correct & Incorrect & Correct & Incorrect \\
\hline Un & 41.7 & 58.3 & 56.3 & 43.8 \\
\hline $\mathrm{D}$ & 48.4 & 51.6 & 57.8 & 42.2 \\
\hline Su & 68.1 & 31.9 & 76.4 & 23.6 \\
\hline $\mathrm{P}$ & 62.5 & 37.5 & 63.9 & 36.1 \\
\hline $\mathrm{R}$ & 59.7 & 40.3 & 68.1 & 31.9 \\
\hline S & 68.1 & 31.9 & 75.0 & 25.0 \\
\hline Total & 54.3 & 45.7 & 63.5 & 36.5 \\
\hline
\end{tabular}

Un: undergraduate students, D: newly-graduated dentists, Su: oral surgeons, P: oral pathologists, R: oral radiologists, and S: stomatologists. 


\begin{tabular}{|c|c|c|c|c|}
\hline Criteria & $\begin{array}{c}\text { AMEL } \\
\text { A }\end{array}$ & $\begin{array}{c}\text { KOT } \\
\text { B }\end{array}$ & $\begin{array}{c}\text { DC } \\
\text { C }\end{array}$ & $\begin{array}{l}\text { IBC } \\
\text { D }\end{array}$ \\
\hline $\begin{array}{c}\text { Radiographic age of } \\
\text { the patient } \\
1\end{array}$ & Non specific & Non specific & $\begin{array}{c}\text { At any age, } \\
\text { common in young } \\
\text { people }\end{array}$ & $\begin{array}{c}\text { Common in young } \\
\text { people }\end{array}$ \\
\hline $\begin{array}{c}\text { Size } \\
2\end{array}$ & $\begin{array}{c}\text { May be smaller than } \\
\text { DC } \\
\text { Usually large }\end{array}$ & $\begin{array}{c}\text { Larger than } \mathrm{DC} \text { or } \\
\text { IBC, and smaller than } \\
\text { AMEL } \\
\text { Small lesions are oval }\end{array}$ & $\begin{array}{l}\text { Usually small and } \\
\text { circumscribed }\end{array}$ & Usually small \\
\hline $\begin{array}{c}\text { Delimitation } \\
3\end{array}$ & Not well-limited & Well-limited & Well-limited & $\begin{array}{l}\text { Not well-limited } \\
\text { Usually mistaken } \\
\text { for AMEL }\end{array}$ \\
\hline $\begin{array}{c}\text { Radiopaque halo } \\
4\end{array}$ & $\begin{array}{c}\text { Rare } \\
\text { Tenuous in small } \\
\text { lesions }\end{array}$ & $\begin{array}{c}\text { Usually present } \\
\text { When absent, a clear } \\
\text { delimitation of the } \\
\text { lesion extension is } \\
\text { observed }\end{array}$ & Common & Absent \\
\hline $\begin{array}{l}\text { Involvement of the } \\
\text { dental element } \\
5\end{array}$ & $\begin{array}{c}\text { May mimic DC } \\
\text { Lesion does not } \\
\text { originate from the } \\
\text { tooth } \\
\text { Tooth encapsulated } \\
\text { by the lesion }\end{array}$ & $\begin{array}{l}\text { May be related to the } \\
\text { tooth, but circular } \\
\text { shape as DC is rare }\end{array}$ & $\begin{array}{l}\text { Circumferential, } \\
\text { lateral, or in a } \\
\text { central position to a } \\
\text { tooth, origin at } \\
\text { cementoenamel } \\
\text { junction }\end{array}$ & $\begin{array}{c}\text { Close to teeth and } \\
\text { their roots, but not } \\
\text { directly related to } \\
\text { them } \\
\text { Interdigitation with } \\
\text { tooth roots }\end{array}$ \\
\hline $\begin{array}{l}\text { Alteration of the } \\
\text { dental element } \\
6\end{array}$ & $\begin{array}{l}\text { Tooth displacement } \\
\text { and resorption }\end{array}$ & $\begin{array}{c}\text { Tooth resorption in } \\
\text { lower degree than } \\
\text { AMEL }\end{array}$ & $\begin{array}{l}\text { Older lesions may } \\
\text { cause tooth } \\
\text { resorption }\end{array}$ & No resorption \\
\hline $\begin{array}{l}\text { Cortical bone } \\
\text { alteration } \\
7\end{array}$ & $\begin{array}{c}\text { Expansion or } \\
\text { disruption in large } \\
\text { lesions }\end{array}$ & $\begin{array}{l}\text { Expansion in large } \\
\text { lesions }\end{array}$ & $\begin{array}{l}\text { Expansion in old } \\
\text { lesions }\end{array}$ & $\begin{array}{l}\text { Rare cortical bone } \\
\text { alteration }\end{array}$ \\
\hline $\begin{array}{c}\text { Base of the } \\
\text { mandible } \\
8\end{array}$ & $\begin{array}{l}\text { Convexity and } \\
\text { resorption }\end{array}$ & Thinning & No alteration & No alteration \\
\hline $\begin{array}{l}\text { Ramus of the } \\
\text { mandible } \\
9\end{array}$ & Commonly affected & Commonly affected & Commonly affected & Rarely affected \\
\hline $\begin{array}{c}\text { Degree of } \\
\text { radiolucency } \\
10\end{array}$ & Homogeneous & Homogeneous & $\begin{array}{l}\text { Homogeneous and } \\
\text { intense }\end{array}$ & $\begin{array}{c}\text { Heterogeneous } \\
\text { (mimics normal } \\
\text { trabecular bone) } \\
\text { and diffuse } \\
\text { (mimics a } \\
\text { multilocular lesion) }\end{array}$ \\
\hline $\begin{array}{c}\text { Growth pattern } \\
11\end{array}$ & Vertical & $\begin{array}{l}\text { Anteroposterior or } \\
\text { medullar }\end{array}$ & $\begin{array}{c}\text { Buccolingual } \\
\text { May be expansive, } \\
\text { but less than AmEL }\end{array}$ & $\begin{array}{l}\text { Little expansive, } \\
\text { unlike AMEL }\end{array}$ \\
\hline $\begin{array}{c}\text { Borders } \\
12\end{array}$ & Variable & $\begin{array}{l}\text { Festooned in large } \\
\text { lesions Smooth }\end{array}$ & Smooth & $\begin{array}{l}\text { Irregular } \\
\text { Smooth }\end{array}$ \\
\hline
\end{tabular}

FIGURE 1- Final diagnostic radiographic parameters. AMEL: ameloblastoma; KOT: keratocystic odontogenic tumor; DC: dentigerous cyst; IBC: idiopathic bone cavity 
TABLE 2- Rates (\%) of correct answers before $\left(T_{1}\right)$ and after $\left(T_{2}\right)$ diagnostic radiographic parameters were given to the examiners, according to type of lesion

\begin{tabular}{lccccccccc}
\hline $\begin{array}{l}\text { Groups of } \\
\text { examiners }\end{array}$ & $\mathbf{T}_{\mathbf{1}}$ & AMEL & $\mathbf{T}_{\mathbf{2}}$ & $\mathbf{T}_{\mathbf{1}}$ & $\mathbf{T}_{\mathbf{2}}$ & $\mathbf{T}_{\mathbf{1}}$ & $\mathbf{T}_{\mathbf{2}}$ & $\mathbf{T}_{\mathbf{1}}$ & KOT \\
\hline Un & 44.4 & 50.0 & 66.7 & 63.9 & 33.3 & 63.9 & 22.2 & 47.2 \\
D & 47.9 & 58.3 & 72.9 & 77.1 & 41.7 & 50.0 & 31.3 & 45.8 \\
Su & 77.8 & 83.3 & 88.9 & 88.9 & 55.8 & 72.2 & 50.0 & 61.1 \\
P & 66.7 & 77.8 & 77.8 & 72.2 & 38.9 & 55.6 & 66.7 & 50.0 \\
R & 72.2 & 77.8 & 61.1 & 72.2 & 44.4 & 66.7 & 50.0 & 66.7 \\
S & 72.2 & 77.8 & 72.2 & 77.8 & 77.8 & 88.9 & 50.0 & 55.6 \\
Averages & 63.5 & 70.8 & 73.3 & 75.4 & 48.7 & 66.2 & 45.0 & 54.4 \\
\hline
\end{tabular}

Un: undergraduate students, D: newly-graduated dentists, Su: oral surgeons, P: oral pathologists, R: oral radiologists, and S: stomatologists. AMEL: Ameloblastoma, DC: Dentigerous cyst, IBC: Idiopathic bone cavity, KOT: Keratocystic Odontogenic Tumor.

TABLE 3- Codes* for criteria most selected at $T_{2}$ by groups of examiners, according to type of lesion and correct or incorrect diagnosis

\begin{tabular}{|c|c|c|c|c|c|c|c|c|}
\hline \multirow[t]{2}{*}{ Groups } & \multicolumn{2}{|c|}{ AMEL } & \multicolumn{2}{|c|}{ DC } & \multicolumn{2}{|c|}{ IBC } & \multicolumn{2}{|c|}{ KOT } \\
\hline & Correct & Incorrect & Correct & Incorrect & Correct & Incorrect & Correct & Incorrect \\
\hline Un & $5 \mathrm{~A}, 6 \mathrm{~A}$ & $3 B, 5 B$ & $1 \mathrm{C}, 5 \mathrm{C}$ & $11 \mathrm{~A}, 3 \mathrm{~B}$ & $1 \mathrm{D}, 3 \mathrm{D}$ & $\begin{array}{l}3 A \\
5 A, 8 A\end{array}$ & $\begin{array}{c}11 \mathrm{~B}, 4 \mathrm{~B} \\
3 \mathrm{~B}\end{array}$ & $\begin{array}{l}1 \mathrm{~A}, 1 \mathrm{C} \\
3 \mathrm{C}, 5 \mathrm{~A} \\
5 \mathrm{C}, 2 \mathrm{~A}\end{array}$ \\
\hline D & $5 \mathrm{~A}, 6 \mathrm{~A}$ & $1 C, 5 \mathrm{C}$ & $3 C, 5 \mathrm{C}$ & $\begin{array}{c}10 \mathrm{~B}, 3 \mathrm{~B} \\
8 \mathrm{~B}\end{array}$ & $3 \mathrm{D}, 5 \mathrm{D}$ & $2 \mathrm{~A}, 3 \mathrm{~A}$ & $\begin{array}{l}2 \mathrm{~B}, 3 \mathrm{~B} \\
4 \mathrm{~B}\end{array}$ & $\begin{array}{l}2 \mathrm{~A}, 5 \mathrm{~A} \\
5 \mathrm{C}\end{array}$ \\
\hline Su & $6 \mathrm{~A}, 7 \mathrm{~A}$ & $\begin{array}{l}10 \mathrm{~B}, 3 \mathrm{C} \\
5 \mathrm{C}\end{array}$ & $5 \mathrm{C}, 6 \mathrm{C}$ & $4 \mathrm{~B}, 8 \mathrm{~B}$ & $1 \mathrm{D}, 3 \mathrm{D}$ & $\begin{array}{l}3 \mathrm{~A}, 5 \mathrm{~A} \\
6 \mathrm{~A}, 8 \mathrm{~B}\end{array}$ & $3 \mathrm{~B}, 4 \mathrm{~B}$ & $1 \mathrm{C}, 4 \mathrm{~A}$ \\
\hline $\mathbf{P}$ & $2 \mathrm{~A}, 6 \mathrm{~A}$ & $1 \mathrm{C}$ & $1 \mathrm{C}, 5 \mathrm{C}$ & $\begin{array}{c}11 \mathrm{~B}, 5 \mathrm{~B} \\
8 \mathrm{~B}, 9 \mathrm{~B}\end{array}$ & $1 \mathrm{D}, 5 \mathrm{D}$ & $\begin{array}{l}1 \mathrm{~A}, 2 \mathrm{~A}, \\
3 \mathrm{~B}, 4 \mathrm{~A}, \\
4 \mathrm{~B}\end{array}$ & $\begin{array}{l}2 \mathrm{~B}, 3 \mathrm{~B} \\
5 \mathrm{~B}\end{array}$ & $2 \mathrm{~A}, 5 \mathrm{C}$ \\
\hline $\mathbf{R}$ & $\begin{array}{r}11 \mathrm{~A}, 2 \mathrm{~A} \\
3 \mathrm{~A}, 5 \mathrm{~A}\end{array}$ & $\begin{array}{l}2 \mathrm{C}, 3 \mathrm{C} \\
5 \mathrm{~B}, 5 \mathrm{C}\end{array}$ & $2 \mathrm{C}, 5 \mathrm{C}$ & $5 \mathrm{~B}, 8 \mathrm{~B}$ & $3 \mathrm{D}, 5 \mathrm{D}$ & $\begin{array}{l}3 \mathrm{~A}, 3 \mathrm{~B}, \\
4 \mathrm{~A}, 4 \mathrm{~B}, \\
8 \mathrm{~B}\end{array}$ & $\begin{array}{c}12 \mathrm{~B}, 3 \mathrm{~B} \\
4 \mathrm{~B}, 5 \mathrm{~B}, \\
8 \mathrm{~B}\end{array}$ & $1 C, 5 \mathrm{C}$ \\
\hline $\mathbf{S}$ & $\begin{array}{l}2 A, 3 A \\
7 A\end{array}$ & $\begin{array}{l}1 \mathrm{C}, 2 \mathrm{~B} \\
7 \mathrm{~B}\end{array}$ & $1 \mathrm{C}, 5 \mathrm{C}$ & $\begin{array}{r}11 \mathrm{~B}, 1 \mathrm{~A} \\
3 \mathrm{~B}, 9 \mathrm{~B}\end{array}$ & $1 \mathrm{D}, 3 \mathrm{D}$ & $4 \mathrm{~B}, 5 \mathrm{~B}$ & $\begin{array}{c}11 \mathrm{~B}, 2 \mathrm{~B}, \\
3 \mathrm{~B}\end{array}$ & $1 C, 5 \mathrm{C}$ \\
\hline
\end{tabular}

* Codes relative to each criterion listed in Figure 1. Un: undergraduate students, D: newly-graduated dentists, Su: oral surgeons, P: oral pathologists, R: oral radiologists, and S: stomatologists. AMEL: Ameloblastoma, DC: Dentigerous cyst, IBC: Idiopathic bone cavity, KOT: Keratocystic Odontogenic Tumor. 


\section{DISCUSSION}

Our purpose in this study was to verify whether previous knowledge of radiographic diagnostic parameters influences diagnostic accuracy in radiographic interpretation of radiolucent unilocular mandibular lesions. Such parameters were obtained in Part I of the study (Figure 1) and informed to distinct groups of examiners in Part II. Regarding examiners in Part II of the study, a significant difference was observed between the values for the moments $\mathrm{T}_{1}$ and $\mathrm{T}_{2}$ of evaluation ( $\mathrm{p}=0.007)$, i.e., the probability of a correct answer (relative to an incorrect answer) was shown to be significantly higher after the diagnostic parameters were known $\left(\mathrm{T}_{2}\right)$. The group of undergraduate students exhibited the highest improvement in the rates of all correct diagnoses $(14.6 \%)$ (Table 1). This information validates the parameters proposed in Part I of the study (Figure 1), since they were based on cases different from those used in Part II of the study. Thus, even when lesions are similar from the radiographic point of view, it is possible to improve diagnostic accuracy after a methodology of analysis is created.

There were significant differences among values for the groups of examiners $(\mathrm{p}=0.003)$, and the probability of a correct answer (relative to an incorrect answer) in the group of specialists is significantly higher than in the groups of undergraduate students or newly-graduated dentists; moreover, these groups did not show difference among probabilities of correct answer. Also, significant differences were not observed among the four groups of specialists, and this was also seen in Part I of this study. Undergraduate students and newly-graduated dentists showed equivalent levels of knowledge on these lesions; Therefore, as stated by van der Stelt ${ }^{20}$ (1993), it may be inferred that only the experience acquired in the exercise of any diagnostic specialty allows increasing the diagnostic accuracy. It was verified that the use of diagnostic parameters contributes to decrease this negative difference in less experienced professionals. For example, when these radiographic parameters were used, undergraduate students and newlygraduated dentists presented results similar to those presented by pathologists and specialists in radiology at moment $T_{1}$ (Table 1). For Mourshed ${ }^{13}$ (1980), teaching students to interpret radiographs adequately is one of the most difficult tasks in Dentistry, since this requires recognizing and interpreting images, which are frequently complex. In this learning process, lesions are grouped by similarity, requiring a long time to learn. Dental schools insist on using such a model of learning. In this model, the student's mental ability is focused mainly on remembering images, which is intellectually frustrating. Mourshed ${ }^{13}$ (1980) suggested another teaching approach, in which diagnostic parameters are used. As far as it could be ascertained, the present study is one of the fewest investigations to demonstrate the validity of such approach in practice. Obviously, diagnosis of a lesion should never be made exclusively on the basis of radiographic interpretation. However, systematic and rational radiographic interpretation with the use of objective criteria contributes undoubtedly to learning with the advantage that it allows lesion diagnosis to be better elucidated.

Regarding examiners' experience, the lowest rates obtained in the correct diagnosis of KOT could indicate that this lesion has less typical characteristics than other unilocular lesions studied herein. The group of undergraduate students in particular exhibited an expressive improvement (from 22.2 at $\mathrm{T}_{1}$ to $47.2 \%$ at $\mathrm{T}_{2}$ ), and their rate for correct answers became reasonably comparable to those from other groups at $\mathrm{T}_{2}$ (Table 2). Inversely, small variations were observed in the rates for correct answers in diagnosing $\mathrm{DC}$ (from $\mathrm{T}_{1}$ to $\mathrm{T}_{2}$ ) for most of the examiners after the list of parameters was given to them. It is probably due to a higher familiarity of all examiners with this type of lesion, including undergraduate students, because this lesion is frequently seen in the graduation course due to its higher relative incidence. The high rate of correct answers presented by oral surgeons $\left(88.9 \%\right.$ at $\mathrm{T}_{1}$ and $\left.\mathrm{T}_{2}\right)$ is coherent with this interpretation. We believe that the act of opening the surgical cavity and observing with naked eyes the cystic capsule in contact with dental surface is a striking experience that leads the oral surgeon to a more careful interpretation of this area in the image, making a correct diagnosis easier. A similar fact occurred in the analysis of other lesions by oral surgeons and stomatologists, indicating that, in some of the analyses, certain diagnostic criteria did not receive the same attention by other groups of examiners.

Since undergraduate students and newly-graduated dentists listed few criteria for KOT and IBC at $\mathrm{T}_{1}$, and also presented a high rate for incorrect diagnoses (Table 2), we can conclude that their knowledge on the several types of images associated with KOT and IBC was very low. The few criteria listed in the analyses of IBC, present in only $10 \%$ of analyses, were usually erroneously done. When the parameters were given to undergraduate students and newlygraduated dentists (at $\mathrm{T}_{2}$ ), in a way, their former empiric criteria for image analysis could be abandoned (Table 3 ). Even specialists, who initially showed to use only the criterion of interdigitation with tooth roots, in IBC (Figure 1, 5D), made more correct diagnoses (Table 2) after additional criteria were included in their analyses (Table 3 ).

The chosen criteria (Figure 1) for each analysis by the examiners, at T2, were also evaluated in this study. One criterion that generated both correct and incorrect answers is related to lesion involvement with the tooth in a circumferential, lateral, or central position (Figure 1, 5C). Thus, except in cases of IBC, a more careful analysis of this involvement is recommended. The lesion is originated in the cemento-enamel junction only in cases of DC (Figure 1, 5C). Teeth embedded into the lesion (Figure 1, 5A), whose radiolucency is not much intense (Figure 1, 10), are more frequent in cases of AMEL. The rounder appearance in this involvement is also more applicable to the cases of DC (Figure 1, 5C).

However, some criteria had their importance confirmed in each type of lesion, such as higher dental resorption in AMEL (Figure 1, 6A), presence of radiopaque halo in KOT 
(Figure 1, 4B), and lack of delimitation (Figure 1, 3D) and young age (Figure 1, 1D) in IBC (Table 3). Furthermore, other criteria did not receive the due attention, such as festooned margins in KOT (Figure 1, 12B), heterogeneous radiolucency in IBC (Figure 1,10D), and distinct growth patterns found in the four lesions (Figure 1, 11).

The use of parameters did allow improving the diagnostic accuracy. Probably, teaching of radiographic interpretation with the use of radiographic parameters in graduation course would make learning easier and less empirical, favoring higher diagnostic accuracy in later professional activity ${ }^{1}$.

\section{CONCLUSIONS}

The use of panoramic radiographic parameters did allow improving the diagnostic accuracy for all groups of examiners, mainly for the undergraduate students group. There were no significant differences between the undergraduate students and the newly-graduated dentists groups considering the diagnostic accuracy. Also, significant differences were not observed among the four groups of specialists.

\section{ACKNOWLEDGEMENTS}

The authors would like to acknowledge the AC Camargo and Heliópolis Hospitals for the radiographs; Professor Líliam Pereira, $\mathrm{PhD}$, for the statistical analysis, and The São Paulo State Research Foundation (FAPESP), for the financial support (Grant 05/54141-8).

\section{REFERENCES}

1- Blesser B, Ozonoff D. A model for the radiologic process. Radiology. 1972;103(3):515-21.

2- Doran GA. A guide to the radiographic interpretation of bone lesions. Aust Dent J. 1984;29:27-9.

3- Eversole LR, Leider AS, Strub D. Radiographic characteristics of cystogenic ameloblastoma. Oral Surg Oral Med Oral Pathol. 1984;57:5727 .

4- Eversole LR, Rovin S. Differential radiographic diagnosis of lesions of the jawbones. Radiology. 1972;105:277-84.

5- Farman AG, Nortjé CJ, Grotepass FW. Pathological conditions of the mandible: their effect on the radiographic appearance of the inferior dental (mandibular) canal. Br J Oral Surg. 1977/78;15:64-74.

6- Hansen LS, Sapone J, Sproat RC. Traumatic bone cysts of jaws: report of sixty-six cases. Oral Surg Oral Med Oral Pathol. 1974;37:899-910.

7- Hofer B, Hardt N, Voegeli E, Kinser J. A diagnostic approach to lytic lesions of the mandible. Skeletal Radiol. 1985;14:164-72.

8- Ikeshima A, Tamura Y. Differential diagnosis between dentigerous cyst and benign tumor with an embedded tooth. J Oral Sci. 2002;44:13-7.
9- Kreidler JF, Raubenheimer EJ, Heerden WFP van. A retrospective analysis of 367 cystic lesions of the jaw - the Ulm experience. J Craniomaxillofac Surg. 1993;21:339-41.

10- Lauria L, Curi MM, Chammas MC, Pinto DS, Torloni H. Ultrasonography evaluation of bone lesions of the jaw. Oral Surg Oral Med Oral Pathol Oral Radiol Endod. 1996;82:351-7.

11- Lipsitz S, Laird NM, Harrington DP. Generalized estimating equations for correlated binary data: using the odds ratio as a measure of association. Biometrika. 1991;78:153-60.

12- Minami M, Kaneda T, Ozawa K, Yamamoto H, Itai Y, Ozawa M, et al. Cystic lesions of the maxillomandibular region: MR imaging distinction of odontogenic keratocysts and ameloblastomas from other cysts. AJR Am J Roentgenol. 1996;166:943-9.

13- Mourshed F. An approach to the teaching of radiographic interpretation of bone lesions. Oral Surg Oral Med Oral Pathol Oral Radiol Endod. 1980;50:92-3.

14- Myoung H, Hong SP, Hong SD, Lee JJ, Lim CY, Choung PH, et al. Odontogenic keratocyst: review of 256 cases for recurrence and clinicopathologic parameters. Oral Surg Oral Med Oral Pathol Oral Radiol Endod. 2001;91:328-33.

15- Nortjé CJ, Rensburg LJ van. Practical insights into the imaging of odontogenic lesions. In: Farman AG, Ruprecht A, Gibbs SJ, Scarfe WC. Advances in maxillofacial imaging. New York: Elsevier Science; 1997. p. 27-34.

16- O’Reilly M, O’Reilly PO, Todd CEC, Altman K, Schfler K. An assessment of the agressive potential of radiolucencies related to the mandibular molar teeth. Clin Radiol. 2000;55:292-5.

17- Raitz R, Correa L, Curi MM, Dib LL, Fenyo-Pereira M. Conventional and indirect digital radiographic interpretation of oral unilocular radiolucent lesions. Dentomaxillofac Radiol. 2006;35:165-9.

18- Scholl RJ, Kellett HM, Neumann DP, Lurie AG. Cysts and cystic lesions of the mandible: clinical and radiologic - histopathologic review. Radiographics. 1999;19:1107-24.

19 Stheeman SE, Mileman PA, Hof M van't, Stelt PF van der. Room for improvement? The accuracy of dental practitioners who diagnose bony pathoses with radiographs. Oral Surg Oral Med Oral Pathol Oral Radiol Endod. 1996;81:251-4.

20- van der Stelt PF. Computer-assisted interpretation in radiographic diagnosis. Dent Clin North Am. 1993;37(4):683-96.

21- Weber AL. Imaging of cysts and odontogenic tumors of the jaw: definition and classification. Radiol Clin North Am. 1993;31:101-20. 